

\section{ÍNDICE}

\section{ÁMBITOS PERSONALES PERSONAL ÁMBITOS}

Crisis de Venezuela: Análisis y perspectivas según los titulares de la prensa argentina, española y china

Venezuela's crisis: Analysis and perspectives in the headlines of Argentine, Spain and China press

Hui Feng Liu

Tratamiento informativo de la violencia de género: asesinatos de mujeres. Análisis de la agencia EFE

Informative treatment of gender violence: murders of women. Analysis of the press agency EFE Rosa Rodríguez Cárcela, Agustín López Vivas

MONOGRAFICOS MONOGRAPHS

Presentación Monográfico. El universo transmedia de los medios de comunicación universitarios: acción dentro y fuera del aula en la sociedad postdigital

Antonia Isabel Nogales-Bocio, Ángels Álvarez villa

El papel transformador de la radio universitaria en materias teóricas ajenas a la comunicación

The transformative role of college radio in theoretical subjects outside communication

Miguel Ángel Díaz Monsalvo

La radiodifusión universitaria: acción discursiva radiofónica para la divulgación de la ciencia University Radio Broadcasting: Radiophonic Discursive Action for the Science Popularization Jorge Sadi Durón, Joel Zapata Salazar

El uso corporativo de Instagram en las universidades privadas españolas. Estudio comparativo de treinta y cinco universidades

The corporate use of Instagram in spanish private universities. Comparative analysis of thirty-five private universities 
La radio universitaria como herramienta de inclusión social: OndaCampus en contextos como la cárcel y barrios desfavorecidos

The university radio as a tool for social inclusion: OndaCampus in contexts like the prison and disadvantaged neighborhoods

Leonor Real Adame, Daniel Martín-Pena, Macarena Parejo Cuéllar

Hacer radio universitaria en la era de YouTube: uso de la plataforma de vídeos a demanda en el contexto mexicano

Make college radio in the age YouTube: use of video on demand platform in the Mexican context Marina Vázquez Guerrero

\section{ARTÍCULOS ARTICLES}

O impresso e o digital nos modelos de negócios de jornais locais: uma análise do Sermos Galiza

The press and digital in business models from local media: Analysis of newspaper Sermos Galiza

Giovanni Ramos

Publicidad y cáncer en la prensa escrita (1903-1912)

Advertising and cancer in the written press (1903-1912)

Laura Almudéver-Campo, Ramón Camaño-Puig

Game rules vs. fandom. How Nintendo's Animal Crossing fan-made content negotiates the videogame meanings

Las reglas del juego vs. el fandom. Cómo el contenido hecho por fans de Nintendo Animal Crossing negocia los significados del videojuego

Jose A. Moreno

La comedia de situación y su análisis textual: evolución de los elementos constructivos del formato

The sitcom and its textual analysis: evolution of the constructive elements of the format

Darío Martín Sánchez

Análisis del discurso emocional de Donald Trump en la campaña electoral de $\mathbf{2 0 1 6}$ Analysis of Donald Trump's emotional speech on the 2016 election campaign 
Innovar, comunicar y transformar (en) la Universidad

Innovate, communicate and transform (at) the University

María Sofía Bernat

288-292

Transparencia en los medios: Un requisito imprescindible para medir la rentabilidad social en radio y televisión

Transparency in the media: An essential requirement to measuresocial profitability in radio and television

Amanda Salazar

Los estudios feministas en comunicación: representación de las mujeres en la revolución tecnológica

Feminist studies in communication: representation of women in the technological revolution 


\title{
Publicidad y cáncer en la prensa escrita (1903-1912)
}

\author{
Advertising and cancer in the written press (1903-1912)
}

\author{
Laura Almudéver-Campo, Universidad de Valencia, \\ C/ Jaime Roig s/n, Valencia, C.P. 46001 \\ Laura.Almudever@uv.es | Orcid: https://orcid.org/0000-0002-3049-4879 \\ Ramón Camaño-Puig, Universidad de Valencia, \\ C/ Jaime Roig s/n, Valencia, C.P. 46001 \\ Ramon.Camano@uv.es | Orcid: https://orcid.org/0000-0002-8018-2232
}

DOI: http://dx.doi.org/10.12795/Ambitos.2020.i47.10

\begin{abstract}
Resumen
El cáncer es una de las enfermedades más graves de nuestro tiempo debido a su elevada prevalencia, morbilidad y mortalidad, lo que la ha convertido en contenido habitual de la información periodística a lo largo de la historia. En este artículo se pretende analizar cómo fueron los anuncios publicitarios relativos a los productos, establecimientos y servicios que se ofertaban a principios del siglo XX en España, en relación con la enfermedad del cáncer, así como realizar una aproximación a la realidad social, cultural y educativa en el periodo de tiempo estudiado.

A partir de la hemeroteca digital de los periódicos $A B C$ y $L a$ Vanguardia, se seleccionaron todos los anuncios publicitarios que aparecieron publicados a lo largo del periodo comprendido entre 1903 y 1912.

Encontramos un total de 386 anuncios (107 en $A B C$ y 279 en La Vanguardia), publicándose el mayor número de anuncios en el año 1910 para el primero y 1903 para el segundo.
\end{abstract}


El tratamiento proporcionado por $A B C$ y $L a$ Vanguardia es bastante diferente en términos numéricos, aunque en los aspectos cualitativos hay niveles de coincidencias importantes, publicándose en ambos medios anuncios idénticos de manera total o parcial.

Las informaciones acerca del cáncer publicadas en la prensa pudieron propiciar en la sociedad una visión excesivamente optimista del tratamiento del cáncer, de sus resultados y de su pronóstico, pues se ofertaban tratamientos con propiedades curativas consideradas excelentes y que poseían características milagrosas.

\section{Abstract}

Cancer is one of the most serious diseases of our time due to its high prevalence, morbidity and mortality, which has made it the usual content of journalistic information throughout history.

This article aims to analyze how advertisements related to the products, establishments and services offered at the beginning of the 20th century in Spain, were related to the cancer disease, as well as to make an approximation to the social, cultural and educational reality in the period of time studied.

From the digital newspaper archive of the $A B C$ and La Vanguardia newspapers, all the advertisements that appeared published during the period between 1903 and 1912 were selected.

We found a total of 386 advertisements (107 on ABC and 279 on La Vanguardia), with the highest number of advertisements published in 1910 for the first and 1903 for the second.

The treatment provided by $A B C$ and La Vanguardia is quite different in numerical terms, although in the qualitative aspects there are levels of important coincidences, with identical or partial announcements being published in both media.

The information about cancer published in the press could have fostered in society an overly optimistic view of cancer treatment, its results and its prognosis, since treatments with curative properties considered excellent and possessing miraculous characteristics were offered.

Palabras clave: Cáncer, publicidad, tratamiento, curación

Keywords: Cancer, advertising, treatment, healing

\section{INTRODUCCIÓN}

Durante la primera década del siglo $X X$, la publicidad fue paulatinamente ocupando cada vez más espacio en diarios y revistas, extendiéndose a lo largo y ancho de las publicaciones. El análisis de los productos anunciados, los mensajes insertados y el 
espacio ocupado, nos da idea de las pautas de consumo y estilos de vida que irrumpieron en la sociedad contribuyendo a los cambios sociales y culturales que pudieron tener lugar (Rodríguez, 2005).

Sin embargo, desconocemos de manera pormenorizada cuál fue el trato informativo que se otorgaba al cáncer y mucho menos el tratamiento publicitario de los aspectos relacionados con esta enfermedad, así como su emplazamiento dentro de la prensa escrita durante el comienzo del siglo XX. A través de las publicaciones periódicas se puede, en cierto sentido, explorar los aspectos intelectuales de la época en relación con la publicidad de productos y servicios relativos al cáncer y llegar a aproximarse con un cierto nivel de detalle tanto a actitudes como a ideologías (Sáiz y Seoane, 1990). Es decir, poder valorar, aunque de manera superficial, cómo fueron los principios de una sociedad de consumo en nuestro país con una serie de productos y servicios relativos a la salud (Alonso y Conde, 1994).

Este estudio pretende analizar la publicidad relativa a los productos y servicios que se ofertaban a principios del siglo XX en relación con una enfermedad como el cáncer y realizar en lo posible, una aproximación a la realidad social, cultural y educativa en el periodo de tiempo comprendido entre el año 1903 y 1912; situando el concepto cáncer en términos contextuales y determinando el significado e imagen que se transmitía junto con el comportamiento publicitario y alcance de las palabras, conceptos, ideas o imágenes empleadas a través de la publicidad insertada en los medios de comunicación escritos. En definitiva, tratar de conocer la imagen transmitida del concepto cáncer, por la prensa en términos publicitarios, concretamente en los dos diarios de información general y de mayor difusión en el ámbito geográfico del Estado Español, de ideología aparentemente distinta, el $A B C$, publicado en Madrid, y $L a$ Vanguardia, publicado en Barcelona, así como analizar y comparar los resultados obtenidos.

\section{MATERIAL Y MÉTODO}

El $A B C$ y su suplemento Blanco y Negro, y La Vanguardia, son dos diarios representativos de las dos ciudades españolas con mayor población en los años de nuestro estudio, con lo que conformaban una parte esencial del nuevo periodismo español, en el periodo comprendido entre el 1 de enero de 1903 hasta el 31 de diciembre de 1912. Ambos periódicos han sido consultados en su versión digital, a través de la hemeroteca digital de los propios periódicos, compaginando su consulta con la versión impresa. La elección de la prensa escrita está justificada por ser el medio publicitario por excelencia, los carteles estaban pasando a un segundo plano y la televisión y la radio se encontraban por desarrollar (Barnicoat, 1997). Se incluyeron en el estudio todos los anuncios publicitarios en cuyo contenido apareciera la palabra cáncer. A continuación, en cada uno de los anuncios seleccionados, en lo sucesivo 
unidades de análisis, que incluian la correspondiente referencia, se procedió a su recuento y clasificación utilizando las categorías de Fernández (2011), de productos, establecimientos y servicios, y cuyo análisis permitió la observación de los datos más relevantes. Por último, se realizó un análisis pormenorizado del contenido de los anuncios publicitarios.

\section{RESULTADOS}

El número de periódicos analizados incluidos en el estudio fue de 7.044 , en concreto 3.414 periódicos de $A B C$ de Madrid junto con su suplemento Blanco y Negro, y 3.630 periódicos de La Vanguardia.

Una vez obtenida la muestra de estudio, se seleccionaron todos los anuncios publicitarios en los que aparecía el concepto cáncer, tal y como se muestra en la Tabla 1 , en la cual se encuentra el número de unidades de análisis por periódico y sus sumatorios.

Tabla 1.

Distribución anual de los anuncios publicitarios en los que aparece el término cáncer.

\begin{tabular}{|c|c|c|c|c|c|c|}
\hline Año/Medio & $A B C+B y N$ & $\%$ & La Vanguardia & $\%$ & Total & $\%$ \\
\hline 1903 & - & - & 40 & $37^{\prime} 4$ & 40 & $10^{\prime} 4$ \\
\hline 1904 & - & - & 1 & $0 ’ 9$ & 1 & 0,2 \\
\hline 1905 & 12 & $4 ' 5$ & 8 & $7 ’ 5$ & 20 & $5 ' 2$ \\
\hline 1906 & 21 & $7 ’ 7$ & 2 & $1 ' 8$ & 23 & 5,9 \\
\hline 1907 & 22 & $7 ’ 9$ & - & - & 22 & $5 ’ 7$ \\
\hline 1908 & 19 & 6'8 & 8 & 7’5 & 27 & 7 \\
\hline 1909 & 26 & 9'6 & 31 & 29 & 57 & $14^{\prime} 8$ \\
\hline 1910 & 73 & $26^{\prime} 3$ & 3 & $2 ' 8$ & 76 & $19^{\prime} 7$ \\
\hline 1911 & 68 & $23^{\prime} 4$ & 3 & $2 ' 8$ & 71 & $18^{\prime} 4$ \\
\hline 1912 & 38 & $13^{\prime} 8$ & 11 & $10^{\prime} 3$ & 49 & $12^{\prime} 7$ \\
\hline TOTAL & 279 & 100 & 107 & 100 & 386 & 100 \\
\hline
\end{tabular}

Fuente: elaboración propia.

Cuantitativamente, en el año 1910 el periódico $A B C$ fue el que mayor número de anuncios relativos al cáncer publicó, con un total de $73(26$ '3\%) unidades de análisis, seguido del año 1911 con 68 (24'3\%) anuncios encontrados y de 1912, con 38 (13'8\%) anuncios. Por otra parte, en el periódico La Vanguardia, el año en el que se publicaron mayor número de anuncios fue 1903, con un total de 40 (37'4\%) unidades de análisis, seguido de 1909, con 31 anuncios y un 29\%.

El análisis pormenorizado de los contenidos de los anuncios exigió que procediéramos a su clasificación por categorías para lo que utilizamos la clasificación de Fernández 
(2011) tal como se ha comentado anteriormente, según la cual se distribuían de la siguiente manera:

a) la publicidad de productos, en la que el contenido del mensaje del anuncio describe las bondades de la mercancía.

b) la publicidad de establecimientos, en la que lo importante es informar acerca de la ubicación, tipo de actividad y artículos disponibles.

c) la publicidad de servicios, en la que los individuos se dan a conocer, ofreciendo al público su profesión y trabajo.

Comenzaremos con el tratamiento de la publicidad de productos. En este apartado encontramos seis productos:

El Bálsamo Maravilloso que se anunció en seis ocasiones únicamente en $A B C$ durante el mes de marzo de 1907, planteando su aplicabilidad interior y exterior contra tisis, cáncer, úlceras y heridas, siendo el precio de la onza de 2,50, y su promotora Josefa Izquierdo, de Criptana (Ciudad Real). No se hacía referencia a los componentes y se hablaba de una posible vinculación con la Monarquía, mediante la expresión entre paréntesis "Real facultad" (Scott, 2007).

El farmacéutico Capmany ofertaba "grageas dinámicas contra el cáncer" en La Vanguardia, mediante un anuncio que se publicó en 17 ocasiones entre enero y mayo de 1903, argumentando que se trataba de una ¡iGran revolución en la medicina!!, y planteaba que "No son ya incurables ni la tisis ni el cáncer", ya que mediante estas píldoras "Se obtiene pronta y radical curación de estas enfermedades en pocos días. Son al propio tiempo el mejor preservativo de ellas y de todas las enfermedades microbianas".

Otro de los productos que se ofertaban fue la Solución Estomacal Sánchez, cuyo anuncio solo se publicó en el periódico La Vanguardia (3 veces en diciembre de 1903 y 17 veces entre abril y octubre de 1909). Unos anuncios que a pesar de aparecer la palabra cáncer avisaban de la falta de utilidad del producto en estos casos. En los anuncios destacaba su titular "El último adelanto de la ciencia médica. La Renovación del estómago o Solución Estomacal Sánchez". En el texto aparece: "Remedio heroico, puramente vegetal e inofensivo, dedicado especialmente a los enfermos crónicos del estómago o reputados incurables. Aseguramos terminantemente en todos los casos (excepto en el cáncer y úlceras de carácter maligno) un éxito completo", una matización interesante, pues se reconoce la inefectividad en caso del cáncer.

Se incluyó la publicidad de un antiácido y antiflatulento denominado Zidal, publicándose en dos ocasiones, una en 1908 y otra en 1909, en La Vanguardia. En los anuncios se afirmaba que "No se ha descubierto el remedio del cáncer" y que "Nada 
reemplaza al Zidal, el solo cura; procure atentamente no ser engañado" afirmando que poseía poder "Renovador de todas las células degeneradas", siendo su composición: hidróxido de aluminio, hidróxido de magnesio, dimetilpolisiloxano y oxetacaina, lo que en la actualidad identificaríamos como un antiácido y antiflatulento recomendado en úlceras pépticas y acidez de estómago.

Bajo el título de "Crónica Médica" y el subtítulo "una causa para varios efectos" y firmado por el Dr. A. Rivas G., encontramos el anuncio del producto Piperacina Midy, que se publicó solamente una vez en 1912 en La Vanguardia, planteando que el producto tenía eficacia como poderoso disolvente del ácido úrico, recomendable en gota, arenilla, reumatismo y artritismo y se ofertaba para el tratamiento del cáncer ya que según el escrito "finalmente el terrible cáncer, no son otra cosa que síntomas del artritismo, hereditario o adquirido", terminando por recomendar a los posibles clientes que procedieran a exigir "la marca Midy" de "venta en las droguerías del país".

Y por último, un producto llamado la Glico-carne concentrada de Laboratorios $\mathrm{M}$. Esteve, que apareció anunciado en varias ocasiones en los dos periódicos analizados. En el periódico $A B C$ aparece con dos formatos publicitarios distintos, en dos ocasiones durante diciembre de 1911, presentando dos tipos de anuncios. En el periódico La Vanguardia, se publicó también con dos tipos distintos de anuncio en diciembre de 1911 y febrero de 1912. Uno de los anuncios de $A B C$ coincide con un anuncio de $L a$ Vanguardia, en el que se destaca el siguiente texto: "El presente os demuestra que debido a los adelantos de la ciencia y gracias a la Glico-carne concentrada de M. Esteve, el noventa y cinco por ciento de las poblaciones viven robustas y sanas". Así mismo, el otro anuncio de $A B C$ era coincidente con el otro anuncio de La Vanguardia, y en el que cabe resaltar el titular: ¿Es usted fuerte? ¡No! Pues la Glico-carne concentrada de M. Esteve os dará la vida. En ambos casos, se ofrece la Glico-Carne concentrada M. Esteve como "Alimento reconstituyente" que es "...de gran utilidad para el cáncer de estómago" a la vez que "es incomparable para el tifus, paludismo y hemorragias".

Todos los productos publicitados en ambos periódicos eran remedios que prometían beneficios a una población con problemas de salud, en este caso, de cáncer. Solo en uno de los casos, la Solución Estomacal Sánchez, se plantea en un alarde de honradez que sus efectos pueden ser esperados en una serie de problemas "excepto en el cáncer y úlceras malignas".

En la categoría de publicidad de establecimientos encontramos cinco establecimientos anunciados en el $A B C$ y siete en La Vanguardia distribuidos de la siguiente manera: en el $A B C$ la Clínica del Cáncer, Establecimiento médico Dr. Díaz de la Quintana, el Instituto del Radio, el Instituto Radiumterápico de Madrid y un establecimiento que procedió a anunciarse como: "consulta enfermedades de la matriz. Curación pronta 
por métodos modernos. Se trata el cáncer con buen resultado, sin operar" y del que solo se aportaba la dirección: "Río, 19".

Por otra parte, los siete establecimientos publicitados en La Vanguardia se distribuyen como sigue: La Policlínica fisio-dinámica Dr. Ballester Marín, el Consultorio Médico L. Salvador Riu, el Instituto Sueroterápico Maragliano, el Gabinete Médico Quirúrgico, el Instituto Radiumterápico (Madrid), y dos establecimientos de los que en uno de ellos aparece la acción terapéutica: "Mentalismo" y en el otro se informa de la ubicación: "Pasaje Reloj".

El primer anuncio que se publicó, apareció solo una vez, en julio de 1905: Clínica del Cáncer, San Vicente, 25, bajo, en el que se ofertaba un "Maravilloso medicamento", que se "Precisa conocerlo en España" y oferta la "Curación segura del cáncer, tumores, úlceras, herpes, heridas aun en casos de gangrena. Sin operación". Termina indicando el horario de visita: "De diez a una diariamente".

El establecimiento médico Dr. Díaz de la Quintana fue anunciado una sola vez en abril de 1907 con el siguiente contenido: "Desde el $1^{\circ}$ de Abril, el establecimiento médico del Dr. Díaz de la Quintana (Huertas, 15, $1^{\circ}$ ) cuenta con personal facultativo y aparatos, para asistir en sus domicilios en Madrid y provincias, a los enfermos de Cáncer, Reuma, Parálisis y Tuberculosis. Baños de luz. - Electricidad. - Masaje. Rayos X.- Inhalaciones. La primera visita (en Madrid), 5 pesetas".

El Instituto del Radio se anunció en 33 ocasiones presentando los anuncios ocho variaciones. La primera aparece en cuatro ocasiones entre octubre y noviembre de 1909. Una única inserción tuvo un anuncio publicado en noviembre de 1909. Todos los anuncios publicados a continuación lo fueron en seis ocasiones cada uno ellos, respectivamente entre enero y abril de 1910, marzo y abril 1910, junio y agosto 1910 y agosto y noviembre de 1910, en esta última tanda se introduce como innovación la imagen de la fachada del edificio en el que se encuentra ubicado el Instituto. La introducción de la imagen se volverá a repetir, en este caso con la imagen de una afectada de cáncer de piel antes y después del tratamiento. En la primera fotografía se puede apreciar el cáncer en la piel de la cara y justo al lado aparece otra fotografía en la que se puede ver la imagen de la afectada con la piel curada mediante aplicaciones radiumterápicas. Estos anuncios se insertaron en cuatro ocasiones con dos variaciones: tres veces los meses de octubre y noviembre de 1910 y en este mismo periodo una vez más con variaciones en el tipo de letra y la organización del anuncio. En todos se insertan grandes titulares, en los que se informaba de los nuevos tratamientos por el radio aplicados a múltiples dolencias incurables hasta ese momento con el siguiente texto: "Cáncer, lupus y manchas de la piel se curan por medio del radium". Dicho instituto se anuncia como uno de los pioneros en aplicar los últimos progresos de la medicina, siendo el único establecimiento y la primera 
fundación en España. Cabe destacar que mientras la consulta de la mañana tenía un precio de 7'5 pesetas, la consulta de la tarde era gratuita.

El Instituto Radiumterápico de Madrid vinculado según la publicidad con la autodenominada Sociedad Española del Radio, ubicado en el Paseo de Recoletos número 31, se anunció en 100 ocasiones presentando los anuncios ocho variaciones que fueron publicadas de forma sucesiva entre febrero de 1910 y mayo de 1912 de la siguiente manera: en febrero de 1910 un primer y único anuncio conteniendo una imagen de la fachada del Instituto Radiumterápico. De marzo de 1910 a diciembre de 1912 se publicó otro anuncio en setenta ocasiones. En cinco ocasiones un nuevo anuncio entre mayo y junio de 1910. En junio de 1910, en tres ocasiones. En noviembre de 1910 otro anunció se publicó en tres ocasiones. Cuatro veces otro anuncio entre enero y febrero de 1911. Entre noviembre de 1911 y diciembre de 1912 se publicó 13 veces otro anuncio diferente. El contenido de los anuncios era bastante similar en las diferentes versiones publicadas y hacía referencia a que el "Cáncer... [lo] curan sin sufrimiento, sin operación y sin grandes molestias por medio del radium" y "sin los enormes gastos ... [que] exigen las intervenciones quirúrgicas". Por otra parte, se hacía referencia al precio de la substancia en la que basaban el tratamiento, entre ellos resalta el siguiente párrafo: "Apenas se concibe que un solo agente posea fuerza tan grande, misteriosa, verdaderamente maravillosa y constante en sus efectos en tan varias afecciones. Lástima que estos beneficios extraordinarios no puedan ser utilizados más fácilmente por el enorme precio de tan escaso y codiciado metal. El enorme precio del radium lo impide. Un solo gramo cuesta 400.000 francos". Por último, en mayo de 1912, bajo el título "Publicidad Recomendada", el Instituto Radiumterápico de Madrid incorpora en un anuncio el siguiente contenido: "Es constante entre los que padecen algunas de las enfermedades conocidas... cáncer... oírles manifestar que están cansados de emplear varios procedimientos para curarse y verles sufrir hasta su muerte desesperada por dolores y problemas... en el Instituto Radiumterápico... hubiesen observado desde las primeras aplicaciones sensible mejoría, y la mayor parte de ellos, su curación".

Otro anuncio se publicó nueve veces en 1905, el cual ofertaba en la calle Río, número 19, una consulta de "enfermedades de la matriz", el primer término resaltado en mayúsculas y ambos en negrita. Y curación pronta por métodos modernos, afirmando que "Se trata el cáncer con buen resultado, sin operar".

En La Vanguardia de Barcelona, se anunció la Policlínica fisio-dinámica del Dr. Ballester Marín en 23 ocasiones, encontrándonos dos variaciones en el formato publicado, el primero de ellos en 20 ocasiones entre julio y octubre de 1903 y una vez más en julio de 1905; el segundo fue publicado en dos ocasiones en enero de 1906, afirmando a los enfermos crónicos, singularmente los de Tisis, Cáncer, Reuma, Estomago, etc., que obtendrán la curación mediante Especiales Tratamientos. 
El Consultorio Médico L. Salvador Riu, publicó un anuncio en cinco ocasiones en 1905, ofertando la "Curación del cáncer".

El Instituto Sueroterápico Maragliano se anunció una sola vez en 1905 y ofertaba la aplicación del "suero Charcot contra el cáncer" y un denominado "suero Maragliano para el tifus y tuberculosis", el Gabinete Médico Quirúrgico publicó un anuncio en siete ocasiones a lo largo de 1908 y ofertaba tratamiento con "Sueroterapia" en el "cáncer de la piel, boca", etc.

Encontramos una sola vez el anuncio del Instituto Radiumterápico de Madrid, durante el año 1910, siendo los contenidos idénticos a aquellos utilizados en el periódico $A B C$, los cuales hemos incorporado en los párrafos anteriores.

Un solo anuncio se publicó en una ocasión en 1910, en el cual bajo la palabra cáncer en mayúsculas se ofertaba la curación "al que lo sufre en sitio visible y se deje fotografiar antes y después de curado". Indicando solo una dirección en la que personarse "Pasaje Reloj, 1, $1^{\circ} 1^{a "}$. En dos ocasiones se insertó un anunció sobre "Mentalismo", el cual se publicó en junio de 1912, ofreciendo la "Curación especial del cáncer" junto con una lista de enfermedades y dando una dirección.

Por último, en la categoría de la publicidad de servicios en la que diferentes profesionales se daban a conocer, ofreciéndose para el tratamiento de diferentes problemas de salud. Los anuncios se distribuyeron de la siguiente manera: dos en el $A B C$, el Prof. G. A. Mann y el Dr. Mateos y cinco en La Vanguardia, el Dr. Nogués Dalmau, el Dr. Mateos de Madrid, el Dr. Roura Oxandaberro, el Dr. Torres Carreras y el Prof. G. A. Mann.

El anuncio publicitario sobre el profesor francés G. A. Mann, se presentaba en dos formatos distintos, uno para el periódico $A B C$ y otro para La Vanguardia en donde procedió a insertar un anuncio anual en 1910, 1911 y 1912. Cabe resaltar el titular y subtítulos, que decían así: "Con su poder fenomenal, este hombre opera milagros". "Los ciegos ven y los paralíticos andan. Los enfermos desahuciados por los médicos son curados por él. No existe enfermedad que no pueda ser curada. Hace desaparecer los dolores, cierra heridas, cura el cáncer, la tuberculosis, los tumores, y opera maravillas que asombran a la Medicina moderna y desafían toda explicación". Se trata de una publicidad de grandes dimensiones en comparación con otros anuncios de la que se desprende mucha esperanza e ilusión para los enfermos de cáncer y que adopta características de noticia con la intención de hacer más creíble y verosímil el contenido. El autodenominado Profesor. G. A. Mann publicó, en el $A B C$, dos anuncios por cada año, en 1905, 1906, 1909, 1910, 1911 y 1912. En 1906, se incluye en uno de los anuncios un huecograbado con la imagen del profesor Mann. En estos anuncios el propio Prof. Mann se presentaba a sí mismo como "Un Gran Taumaturgo" y continuaba diciendo de sí mismo: "Hace desaparecer los dolores, cierra 
las heridas, cura el cáncer", "No existe enfermedad que no pueda ser curada" e incluso decía que procedía a realizar la "Cura a distancia", invitando a los médicos a que le llevaran a sus pacientes incurables. Afirmaba en última instancia "obtener la curación por medio de la radiopatía", que según el propio autor procedía de una "fuerza síquica muy sutil, ayudada de preparaciones magnéticas que contienen los principios mismos de la vida y la salud".

Una nueva publicidad ofrecía los servicios del doctor Mateos, tanto en la calle Preciados $n^{\circ} 28$ de Madrid, como en la calle Arenal, $n^{\circ} 1$. Una publicidad que anunciaba la "Cura del Cáncer sin Operación" a través de ocho formatos publicitarios distintos, y empleando diferentes tipografías, siendo el conjunto de anuncios publicitarios de 115, tal y como pasamos a comentar en número y fechas. En $A B C$ se publicó entre marzo y octubre de 1906 (15 anuncios), entre enero de 1906 y enero de 1907 (6 anuncios), entre enero y noviembre de 1907 (13 anuncios), 38 anuncios entre marzo de 1908 y diciembre de 1909, entre enero y septiembre de 1910 (14 anuncios), nuevamente 14 anuncios entre octubre de 1910 y octubre de 1911 y finalmente 15 anuncios entre abril de 1911 y octubre de 1912. En La Vanguardia solo se publicó, en una ocasión, el 14 de septiembre de 1904 en la portada. En los anuncios se ofrece la "Cura del Cáncer sin Operación" y las "consultas pueden realizarse por carta". Los anuncios tenían todos contenidos similares cambiando la tipografía y su distribución en la hoja del periódico, siendo habitualmente en una columna, con texto idéntico al que se añadía las patologías a ser tratadas y se ampliaba la oferta de servicios. El procedimiento terapéutico a utilizar se le denominaba: "Debreyne" interno y externo. Un compuesto a base de vino en el que, en función de ser externo o interno, se podían modificar los componentes. En seis de las variaciones aparece la palabra Matriz con tipo de grafía, tamaño y ubicación diferentes. Siendo un diseño clásico el que aparecía en negrita: "Cáncer y tumores malignos" y ofertaba: "cura sin operación, alivio rápido siempre”.

En La Vanguardia se publicaron además los siguientes anuncios: El Dr. Nogués Dalmau, de Mallorca, publicó un solo anuncio en 1903, en la que describió su actividad "Curando el cáncer sin operaciones". El Dr. Roura Oxandaberro publicó un solo anuncio en 1905, ofertando en mayúsculas la "Curación del Cáncer, lupus, tumores, etc., por el nuevo tratamiento del Radium"; y el Dr. Torres Carreras publicó 13 anuncios en dos formatos distintos, siendo uno de ellos publicado en 12 ocasiones entre marzo y agosto de 1909, el otro solo se publicó en una ocasión, en agosto 1909. El anunciante se presentaba como "alumno del hospital de París" y ofrecía "tratamiento del cáncer por fulguración, diagnóstico, fotografía y tratamiento por los Rayos X, electro-foto-iono-terapia y altas frecuencias [sic]". 


\section{DISCUSIÓN}

La publicidad se utilizó a principio del siglo XX, tal y como se utilizaría en la actualidad, tratando de proporcionar información acerca de los productos y creando interés, tanto en los consumidores como en aquellos que pudieran serlo en el futuro.

Por tanto, es necesario hacer consideraciones acerca del acceso a la lectura, dado que era determinante para poder decodificar las informaciones contenidas en los periódicos de la época. Es necesario tenerlo en cuenta puesto que un porcentaje muy alto de la población no sabía leer ni escribir, estableciéndose en 1910 en torno al $52 \%$ de la población: $39 \%$ en los hombres y $61 \%$ en las mujeres (Calvo, 2011), lo que determinaba el acceso al conocimiento preventivo y terapéutico respecto de problemas de salud, tales como el cáncer. La pertenencia a un nivel social u otro, establecía el nivel de alfabetización y por tanto, era concluyente para poder acceder a las fuentes de información respecto a la salud, una situación que hoy como ayer, se mantiene.

En los anuncios se proporcionaba información acerca de la empresa, profesionales y productos, sus cualidades, puntos de venta, etc., con el objetivo de incrementar las ventas, especialmente en los casos en los que existía competencia e incluso se llamaba la atención a los clientes acerca de la existencia de posibles imitaciones. Su utilidad se hizo pronto patente desde la perspectiva en que se informaba y educaba a las personas acerca de los productos y servicios, y por supuesto, sus usos y aplicaciones, permitiéndoles la adopción de nuevos hábitos y planteamientos y el abandono de actitudes y acciones obsoletas, contribuyendo a la mejoras del nivel de vida. Bori y Gardó (1931) afirmaban en un capítulo de su libro Tratado completo sobre publicidad y propaganda, que lo que "justifica la utilización del reclamo es que ha sido de tal magnitud la complicación introducida en el comercio, que hay una infinidad de productos para una misma finalidad que se disputan simultáneamente el favor del consumidor".

La publicidad emitida en una época puede mostrarnos ciertas características de la sociedad en la que se desarrolla, comenzando desde el tipo de productos y servicios que se producían, ofrecían y vendían, hasta las novedades que aparecían en el mercado, su uso, explicaciones, sugerencias y distribución a los potenciales consumidores (Rodríguez, 2005). Tanto por su número como por su trascendencia social, las publicaciones periódicas se erigían como el único medio del panorama intelectual por el que se podían conocer con cierto detalle las actitudes e ideologías del momento (Sáiz y Seoane, 1990), tal y como así ocurre, pues nos informaban, por ejemplo, de la vigencia en ese momento de la teoría infecciosa para la explicación del cáncer a partir de la publicidad de procesos de sueroterapia, en coexistencia con charlatanes que ofertaban el mentalismo, la Radiopatía o fuerza psíquica sutil, ayudada por el magnetismo. 
En estos primeros años del siglo XX, el mercado publicitario en prensa se caracterizó por su inestabilidad. La escasez de anunciantes y la poca diversidad de los productos publicitados eran el reflejo de que en aquellos años los primeros pasos de la sociedad de consumo en España eran todavía muy incipientes.

Altabella (1963) explica el proceso de transición e itinerario que siguieron los anuncios en prensa diaria desde el momento en que "surgió el anuncio, el imperio naciente de la publicidad, manifestada tibiamente en la cuarta plana, y después en las restantes hasta asaltar la primera". Unos anuncios que en su mayoría, fueron textos que se insertaron en columnas verticales, con tipografías diferentes para destacar los productos publicitados, y que en ocasiones incluyeron ilustraciones muy simples, a veces copiadas de publicaciones extranjeras (Rodríguez, 2007). Los anunciantes supieron percibir los efectos que los anuncios producían en los posibles consumidores y como consecuencia, la publicidad fue adquiriendo una mayor importancia.

El periódico $A B C$, que inició su andadura en 1903, tuvo problemas para captar publicidad en sus primeros números, de tal manera que los anuncios relacionados con cáncer solo llegaron a partir de 1905. La mayor cantidad de piezas se acumuló entre 1909 y 1912, produciéndose en este último año un ligero descenso. El crecimiento en el número de anuncios nos hace pensar que este sector seguía la misma tendencia que se estaba produciendo a nivel de la publicidad en general. El tratamiento proporcionado por $A B C$ y $L a$ Vanguardia es bastante diferente, en términos numéricos aunque en los aspectos cualitativos hay niveles de coincidencias importantes, publicándose en ambos medios anuncios idénticos de manera total o parcial.

Los datos obtenidos nos permiten hablar en España de una lenta, pero progresiva consolidación del mercado publicitario. La prensa aumentó el número de páginas dedicadas a la publicidad; por tanto, se había incrementado el número de anunciantes y de productos publicitados modificándose la ubicación y el tratamiento tipográfico de los anuncios. La imagen fue adquiriendo protagonismo y los mensajes publicitarios, depurándose. A finales del siglo XIX, la introducción del grabado en color y del reportaje fotográfico transformó radicalmente la prensa ilustrada (Seoane, 1992), aunque fue una situación que tardó en trasladarse a los periódicos, tal y como se desprende de nuestros datos. Algo que no fue obstáculo para que a medida que avanzamos en el tiempo, la imagen llegara a protagonizar casi en exclusiva el anuncio en detrimento del texto.

En esta línea, los anuncios estudiados muestran muy pocas imágenes, lo cual es, al tiempo, coincidente con la situación en el mercado publicitario del momento. Las imágenes se encuentran solo presentes en el periódico $A B C$. La publicidad insertada por el profesor Mann, en 1906, incorporó un huecograbado con su imagen. La fotografía fue incluida en este tipo de anuncios unos años más tarde, siendo el Instituto 
Radiumterápico de Madrid el primero que publicó la imagen de la fachada de su sede en un anuncio de febrero 1910; más tarde, a lo largo de ese mismo año el Instituto del Radio incorporó la fachada de su sede en un anuncio publicado en seis ocasiones entre agosto y noviembre de 1910. Posteriormente, de manera innovadora para la época, la utilización de la imagen de pacientes, algo inconcebible en el momento actual ya que no había restricciones es ese sentido. El Instituto del Radio insertó en un anuncio publicado cuatro veces, durante el otoño de 1910, con dos variaciones en términos de tipografía y distribución del texto, una fotografía de una paciente antes y después, de haberla sometido a tratamiento con radium. Esta tímida utilización de la imagen a partir de 1910 indica un proceso de actualización y adaptación a las tendencias del momento.

Transcurre muy poco tiempo entre la identificación de la posible utilización del radium y los rayos $X$ como posibles tecnologías diagnósticas y terapéuticas y su publicitación y aplicación generalizada. En nuestra muestra, la primera inserción publicitaria detectada que habla del radium apareció en La Vanguardia y fue insertada por el Dr. Roura Oxandaberro en una única ocasión en 1905, que ofertaba la curación del cáncer, entre otras cosas, por el "nuevo tratamiento del radium". En 1907 el ABC insertó un único anuncio del Establecimiento médico Dr. Díaz de la Quintana, haciendo referencia a los Rayos X. Estos datos no son indicativo de que fueran los primeros en utilizar este tipo de tecnologías, pero sí se puede entender que pudieron ser los primeros en comprender que estas tecnologías tenían un elemento distintivo que les podría favorecer en cuestiones de competencia a la hora de anunciarse.

De hecho, la única terapia que hasta ese momento se utilizaba en pacientes con cáncer con un cierto nivel de éxito era la cirugía, la cual se aplicaba de manera radical y dejando en la mayoría de los casos, importantes secuelas en cuestión de imagen corporal e impotencia funcional. La aparición de nuevos procedimientos terapéuticos como el radium hizo pensar a los profesionales sanitarios del momento, en la posibilidad de obtener la curación sin necesidad de recurrir a la cirugía, tal y como así se manifiesta en un importante número de los anuncios estudiados; y a los pacientes, la posibilidad de librarse de las secuelas de la cirugía. En un conjunto de veintiséis anunciantes en ambos periódicos, si eliminamos los fármacos anunciados y los anuncios que se repiten en ambos medios, así como los anuncios insertados por el prof. Mann y el que oferta "mentalismo", podemos observar que, de quince anunciantes, el $46,6 \%$ (7) oferta la curación sin operaciones.

Las informaciones acerca del cáncer publicadas en la prensa pudieron propiciar en la sociedad una visión excesivamente optimista del tratamiento del cáncer, de sus resultados y de su pronóstico, pues se ofertaban tratamientos con propiedades curativas consideradas excelentes y que poseían características milagrosas. De hecho, los anuncios incorporaban textos tales como: "Curación segura del cáncer", 
"Curación pronta por métodos modernos", "Cura del cáncer sin operación", "-sin dolor y sin dejar huella- de múltiples dolencias consideradas incurables hasta el día de hoy", "Cáncer... se curan sin sufrimiento, sin operación y sin grandes molestias por medio del radium", etc., un conjunto de expresiones que querían transmitir seguridad y confianza, pero que estaban alejadas de la realidad.

De alguna manera, la aparición de estos productos significó un cambio cualitativo, la enfermedad se hizo negocio, o tal y como dice Puerto (2004): "Los específicos, se quiera o no, tienen un componente económico imposible de ocultar". El medicamento se transforma en un objeto industrializado, sujeto a leyes de mercado y consumo; se aleja de lo científico y comienza a anunciarse en los medios de comunicación escritos. Se inicia una etapa de la que ya habían dado testimonio algunos miembros de la profesión médica a mediados del siglo XIX: "La Medicina no puede tolerar ni aprobar tantos anuncios, tantos prospectos, tantos folletos, tantos librotes de ignorancia, de engaño, de especulación y de farsa médica: y por tanto los reprueba de la manera más solemne, como perjudiciales a la salud" (Codinach, 1854). Una situación de la que parece ser, siempre según la misma fuente, que aquellos profesionales que entraban en el proceso de anunciarse podían obtener pingües beneficios a través de la proyección de su imagen: "el boticario que anuncia, ó de cualquier modo publica medicamentos, da lugar á pensar á las gentes sencillas, que él es mejor boticario que los otros que no las publican" (Codinach, 1854).

Tras el estudio de estos anuncios se desprende la gran utilidad que va adquiriendo la publicidad que se plasma en la famosa frase de "quien no se anuncia no se vende" (Rodríguez, 2007), lo que se traduce en que existían establecimientos que no eran conocidos porque no se anunciaban, demostrando que la publicidad en el periodo que estamos estudiando servía y mucho, para sus propósitos. En concreto, parece ser así, cuando al final del periodo analizado, podemos ver como el Instituto Radiumterápico, que había insertado cien anuncios en el $A B C$, o el Dr. Mateos máximo anunciante en el $A B C$ con ciento quince anuncios, deciden publicar un anuncio cada uno en $L a$ Vanguardia, con la intención de atraer clientes de fuera de la capital.

La evolución de este tipo de publicidad, teniendo en consideración el tipo de mensaje y los posibles resultados podría explicarse desde dos perspectivas, la primera surge al constatarse, en términos generales, una baja esperanza de vida, en el "año 1900, la mortalidad española reducía la esperanza de vida al nacer a unos 33,8 años para los hombres y 35,1 para las mujeres, con niveles para ambos sexos inferiores en 15 años a la media de los países de Europa Occidental" (Cabré, Domingo y Menacho, 2002), y por otra parte, la propia competitividad y los beneficios percibidos a raíz de ésta, dado que de otra manera podría no haberse dado la necesidad de contratar publicidad. 


\section{CONCLUSIONES}

A lo largo de nuestro trabajo hemos podido apreciar que los medios de comunicación han estado de manera continuada facilitando información en relación con aspectos tales como la prevención, el diagnóstico y el tratamiento del cáncer acorde a los conocimientos de la época, es decir, que han tratado de proporcionar respuesta de una manera constante a las necesidades de información de la población.

En esta investigación hemos querido conocer cómo era la publicidad en relación con el cáncer, concretamente en dos diarios de ideología, aparentemente distinta, el $A B C$ y La Vanguardia, identificando los anuncios publicitarios publicados sobre ello, así como analizando y comparando los resultados obtenidos.

El tratamiento proporcionado por ambos medios, en términos cuantitativos, es bastante diferente, con la utilización de elementos cualitativos similares y la coincidencia de la presencia de algunos anuncios en los dos periódicos.

Hemos visto, en conclusión, que en los primeros años del siglo XX en España, la prensa aumentó el número de páginas dedicadas a la publicidad, al igual que se incrementó el número de anunciantes y de productos publicitados. Mejoraron las características tipográficas de los anuncios, y se insertó la imagen y fotografía como reclamo al consumidor. Estos datos nos permiten hablar de la progresiva consolidación de un mercado publicitario desde el primer decenio del siglo XX. Así pues, la publicidad fue el escaparate privilegiado a través del cual se presentaron los nuevos productos que comenzaron a inundar el mercado, a la vez que se constituyó como la herramienta por excelencia para introducir nuevas pautas y hábitos de consumo en la sociedad, sirviendo además, como anticipadora y difusora de los nuevos estilos de vida, de las nuevas costumbres y de los nuevos roles de la sociedad de consumo.

Para los publicitarios significó además un campo de experimentación, tanto en contenidos como en decisiones sobre difusión. Era necesario llamar la atención sobre qué era y cómo se usaban los distintos adelantos. Medicinas, remedios y licores, recurren a la publicidad para darse a conocer, publicitándose las cualidades milagrosas de sus pociones curativas, aunque a veces quedaba patente la falta de escrúpulos y escasa ética de muchos promotores de medicamentos, capaces de publicitar sus esencias cuando en realidad se trataba de fórmulas descabelladas, del todo inútiles para los fines terapéuticos previstos.

Se fabricaron medicamentos de forma masiva y aumentaron sus variedades y usos, de modo que también necesitaban comunicarlo al público. La carga informativa empieza a ceder en los anuncios de prensa, las tipografías se basaban cada vez más en diseños llamativos y las imágenes que incluyen rompen la uniformidad de la página y atraen la 
mirada de los lectores. De hecho se observa que a medida que fue depurándose el diseño de los anuncios, se pasó de la sencillez de presentar el producto y enunciar sus características, a vender sensaciones y a enseñar las vidas de los consumidores mejoradas por el uso de los productos ofertados.

En este sentido, tal y como hemos podido ir constatando a lo largo de nuestro trabajo, los medios de comunicación escrita, y los anuncios que en sus páginas se plasmaban, han tenido y tienen el potencial de influir sobre los conocimientos, las actitudes y los comportamientos de la población, en relación con una determinada enfermedad. Y el cáncer, considerado incurable, era una de ellas.

\section{Referencias}

Alonso, L. E. y Conde, F. (1994). El nacimiento de la sociedad de consumo en España: una aproximación a sus orígenes y primer desarrollo. Madrid: Debate.

Altabella, J. (1963). La Correspondencia de España. Notas para una historia de la publicidad. Información de la Publicidad, 7, 15-18.

Barnicoat, J. (1997). Los carteles, su historia y su lenguaje. Barcelona: Gustavo Gili.

Bori, R. y Gardó, J. (1931). Tratado completo sobre publicidad y propaganda, Tomos I y II, Barcelona, José Montesó editor, 1931 (segunda edición revisada y aumentada en 1936), 14-15.

Cabré, A., Domingo, A. y Menacho, T. (2002). Demografía y crecimiento de la población española durante el siglo XX. En Pimentel Siles, M. (coord.). Mediterráneo Económico, 1. Monográfico: Procesos Migratorios, economía y personas, 121-138, Almería: Caja Rural Intermediterránea.

Calvo, C. (2011). De la alfabetización a las enseñanzas medias de las personas adultas en Aragón. Apuntes para su historia. En Guillermo Vicente y Guerrero (Coord.). Historia de la Enseñanza Media en Aragón. Zaragoza: Institución Fernando El Católico (C.S.I.C.).

Codinach, E. (1854). Una medicina nueva para curar la manía de los publicadores, vendedores y compradores de medicinas llamadas específicas. Barcelona: Imprenta de A. Verdeguer. Recuperado de: http://books.google.es/books/ucm?vid=UCM5320137066\&printsec=frontcover\&redir_es $\mathrm{c}=\mathrm{y} \# \mathrm{v}=$ onepage \&q\&f=false. Web visitada el 12/05/2013.

Fernández, $M^{a} D$. (2011). La publicidad de salud en la prensa ilustrada de finales del siglo XIX. Questiones Publicitarias, 1(16),108-124.

Puerto, F. J. (2004). El medicamento en el escaparate: la publicidad farmacéutica en España, una aproximación histórico-literaria. Barcelona: Fundación Uriach, colección histórica de ciencias de la salud, $n^{\circ} 8$. 
Rodríguez, N. (2005). Hábitos de consumo y publicidad en la España del primer tercio del siglo XX, 1900-1936, en Actas de las VII Jornadas de Castilla-La Mancha sobre investigación en archivos "España entre Repúblicas 1868-1939". Guadalajara, 15-18 de Noviembre de 2005, (en prensa).

Rodríguez, N. (2007). Anunciar es vender: nacimiento y desarrollo de la publicidad en la España del primer tercio del siglo XX. I Encuentro de Jóvenes Investigadores en Historia Contemporánea de la Asociación de Historia Contemporánea: Zaragoza, 26, 27 y 28 de septiembre de 2007.

Sáiz, D. y Seoane, M. C. (1990). Historia del periodismo en España. Madrid: Alianza Universidad.

Seoane, Ma C. (1992). Historia del periodismo en España. 2. El siglo XIX. Madrid: Alianza Universidad Textos.

Scott, A. L. (2007). The stories we sell: A narrative analysis of direct-to-consumer pharmaceutical advertising. Doctoral dissertation. University of Texas. Recuperado de: https://repositories.tdl.org/utmbir/bitstream/handle/2152.3/118/AngelaScottDissertation. pdf.txt?sequence=3. 